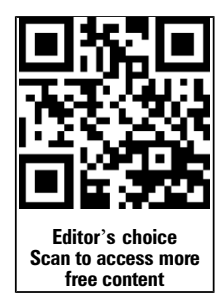

Correspondence to

Dr Seng Eun Choi, Department

of Government Expenditure,

Korea Institute for Public

Finance, 79-6 Garak-dong,

Songpa-gu, Seoul, Korea;

sechoi@kipf.re.kr

Received 18 March 2014 Accepted 7 November 2014

Published Online First

27 November 2014

\section{SLinked}

- http://dx.doi.org/10.1136/ tobaccocontrol-2014-052104

\section{CrossMark}

To cite: Choi SE. Tob Control 2016;25:141-146.

\title{
Are lower income smokers more price sensitive?: the evidence from Korean cigarette tax increases
}

\author{
Seng Eun Choi
}

\begin{abstract}
Background The cigarette excise taxes and the price

the associated price rise is largely borne by higher income smokers.
\end{abstract} of a typical pack of cigarettes in Korea have not increased since 2005, and effective tax rate as a fraction of price and real price of cigarettes have both been falling. As smoking prevalence is higher among lower income people than among higher income people in Korea, the regressivity of cigarette excise taxes is often cited as a barrier to tobacco tax and price policy. While studies in several other high-income countries have shown that higher income individuals are less price sensitive, few studies have examined the differential impact of cigarette tax increases by income group in Korea. Most of the Korean literature has estimated the demand for cigarettes using time-series aggregate sales data or household level survey data, which record household cigarette expenditures rather than individual cigarette consumption. Studies using survey data often lack time-series variation and estimate cigarette demand using household expenditure data, while studies using time-series aggregate sales data lack cross-sectional variation.

Objective I examine differences in the effects of cigarette price on the cigarette consumption of various income groups using individual-level cigarette consumption records from the Korea National Health and Nutrition Examination Survey (KHNNES). I also analyse the implications of cigarette taxes and price increases on the relative tax burdens of different income groups.

Design I use pooled data from the KNHNES for the 1998-2011 period to estimate the price elasticity of cigarette consumption of four income groups. Treating cigarette consumption as a latent variable, I employ an econometric procedure that corrects for non-random sample selection, or the fact that some non-smokers might have smoked at a low enough price, and estimate the price elasticity of cigarette consumption by income group. The estimated price elasticities include the responsiveness of potential smokers as well as current smokers.

Results Lower income Korean smokers are more responsive to changes in the price of cigarettes. While the overall price elasticity of cigarettes is estimated to be -0.425 , the price elasticity of the lowest income quartile is estimated to be -0.812 , whereas that of the highest income quartile is estimated to be -0.325 .

Conclusions The estimated price elasticities of different income groups imply that the cigarette tax and price increases in Korea would reduce smoking more in those with lower incomes. For a given price increase, the percentage reduction in cigarette consumption among smokers in the lowest income quartile is 2.5 times greater than among smokers in the top income quartile. The simulated tax burdens of different income groups show that the additional burden of a tax increase and

\section{INTRODUCTION}

The price of cigarettes in Korea is the lowest among Organisation for Economic Co-operation and Development (OECD) countries, while the prevalence of smoking in men is the highest among OECD countries. ${ }^{1}$ According to the Ministry of Health and Welfare Statistical Yearbook, the prevalence of smoking in men decreased from $67 \%$ in 1998 to $45.1 \%$ in 2007, but has slightly increased to $46.8 \%$ since $2007 .^{2}$ The price of cigarettes in Korea were increased only six times during the past 25 years: the price of a typical pack of 20 cigarettes was 900 won in 1994 and was raised to the current price of 2500 won in 2005. Accounting for inflation, a pack of 2500 won in 2014 is equivalent to 2000 won in 2005.

Korea imposes a local government excise tax of 641 won (equivalent to US\$0.6), a local education tax amounting to $50 \%$ of the local government excise tax, an earmarked excise tax of 354 won, $10 \%$ value added tax and waste disposal tax of 7 won on 20 cigarettes. Total tax on a typical pack of cigarettes is 1550 won, amounting to $62 \%$ of the price of a pack of cigarettes. Local government excise tax was raised twice from 461 won to the current level of 641 won and local education tax was introduced in 1996. An earmarked excise tax was introduced in 1997 as a source of revenue for the National Health Promotion Fund.

The cigarette manufacturing industry in Korea was previously a government-owned monopoly, and the price of a typical pack of cigarettes was set by the government until Korea Tomorrow and Global (KT\&G) was finally privatised in 2002. Following privatisation of KT\&G and price deregulation, however, the long tradition of cigarette price regulation has largely persisted. As a consequence, although premium cigarette brands were being introduced with high prices, the price of a typical pack of cigarettes has not changed, given the absence of cigarette tax changes. Raising cigarette excise taxes and price is frequently considered as a tobacco control policy to reduce smoking prevalence and also as an additional revenue source for financing welfare expenditures.

One of the main arguments associated with cigarette tax increases in Korea is that cigarette excise taxes are regressive. Product taxes on most goods, excluding luxury goods, are typically considered regressive because the ratio of consumption expenditures to income is greater among the poor than among the wealthy. The regressivity of cigarette 
excise taxes is compounded by the fact that the poor in many countries generally smoke more than the rich, so that cigarette taxes fall disproportionately on the poor. This is also true of Korea: in 2011, smoking prevalence among adults in the lowest income quartile was $30.8 \%$, while that among adults in the highest income quartile was $24.1 \%$. However, an important argument to counter concerns of regressivity is that the additional tax burden associated with tax increases may be less for lower income groups if they are more responsive to cigarette price increases than higher income individuals. Increases in cigarette taxes and price may reduce the regressivity of existing cigarette taxes, depending on the price elasticities of different income groups.

The empirical questions of how responsive cigarette consumption is to price changes and how responses would vary by income groups are important to the estimation of the effectiveness of tobacco tax and price policy for tobacco control and tax revenue. While previous studies of the price elasticity of cigarette consumption in Korea reports various magnitudes of elasticity for the aggregate population, depending on the data and econometric estimation strategies used, few studies have examined the price elasticity by income groups. ${ }^{3-9}$

The paper estimates the differential responsiveness of cigarette consumption to price changes for income groups by using the Korea National Health and Nutrition Examination Survey (KNHNES), which reports official national smoking-related statistics. KNHNES is an individual level survey data with information on individual-level cigarette consumption and varied smoking-related information, such as the duration of smoking, cessation of smoking and past smoking experience. Pooling the survey data across years provides time-series as well as crosssectional variation in smoking habits of individual smokers.

\section{Previous literature}

Previous studies of the price elasticity of cigarettes have generally found that the demand for cigarettes is price inelastic. ${ }^{10-13}$ Gallet and List ${ }^{14}$ reviewed 500 studies and concluded that the price elasticity of cigarettes is -0.4 to -0.44 . The demand for cigarettes is found to be more price-responsive in low-income countries, low-income smokers and younger smokers. Most of these studies have estimated the price elasticity of -0.25 to -0.5 for high-income countries. ${ }^{15}$ For low-income and middle-income countries, the price elasticity is estimated to range from -0.5 to -1 . A recent extensive survey of the literature has found estimates of overall price elasticity to range from -0.2 to -0.66 for high-income countries, and from -0.154 to -1.62 for lowincome and middle-income countries. ${ }^{16}$ While lower income groups are consistently found to be more responsive to cigarette price increases in high-income countries, this is not always the case in low-income and middle-income countries.

Korean studies have also produced estimates of the price elasticity of cigarette demand that range from -0.19 to -0.77 . Most studies of the price elasticity of cigarettes in Korea have used aggregate time-series sales data ${ }^{3-5}$ and Household Expenditure and Income Survey data. ${ }^{3-9}$ Studies based on aggregate data have estimated price elasticities ranging from -0.24 to -0.47 , and studies based on survey data have estimated price elasticities ranging from -0.19 to -0.77 .

It is well recognised that aggregate time-series data suffer from multicollinearity problems and simultaneity problems that introduce statistical biases in the estimate of price elasticity. Aggregate time-series data also lack information on individual decision-making. ${ }^{17}$ Individual-level data provide more information on smoking prevalence, cessation decisions and the effect of addiction. Previous studies of cigarette consumption in Korea have used the Household Expenditure and Income Survey, which provides long time-series spans as well as cross-sectional information; that survey, however, only records household expenditures on cigarettes rather than individual quantities of cigarettes consumed.

In addition to limitations in previously used data sources, most Korean studies have not fully examined the effect of the most conspicuous price increases in 2005. Among the six price increases from 1996 to the present, the price increases in 2004 and 2005 were very steep compared with the earlier price increases. The price per pack of 20 cigarettes was 1500 won before December 2004, when it rose to 2000 won. After 1 month, the price became 2500 won on January 2005 (see figure 1). In only 2 months, cigarette pack price rose from 1500 won to 2500 won. The four prior price increases in the 1990s and in 2002 involved much smaller increases of 100 won to 200 won. Earlier studies of Korean cigarette demand primarily analysed the 1990s and early 2000s, and the most recent studies examined data through 2006.

\section{Data and variable descriptions}

The paper uses individual smoking-related records in the KNHNES. The survey was conducted every 3 years from 1998 to 2007, and it was changed to an annual survey in 2007. Although they are not panel data, repeated cross-sectional data provide sufficient time variation and cross-sectional variation. The survey records the age that individuals began smoking, their motivation for smoking, average cigarette consumption per day of current smokers and ex-smokers, the duration of
Figure 1 Cigarette excise taxes and cigarette prices in Korea.

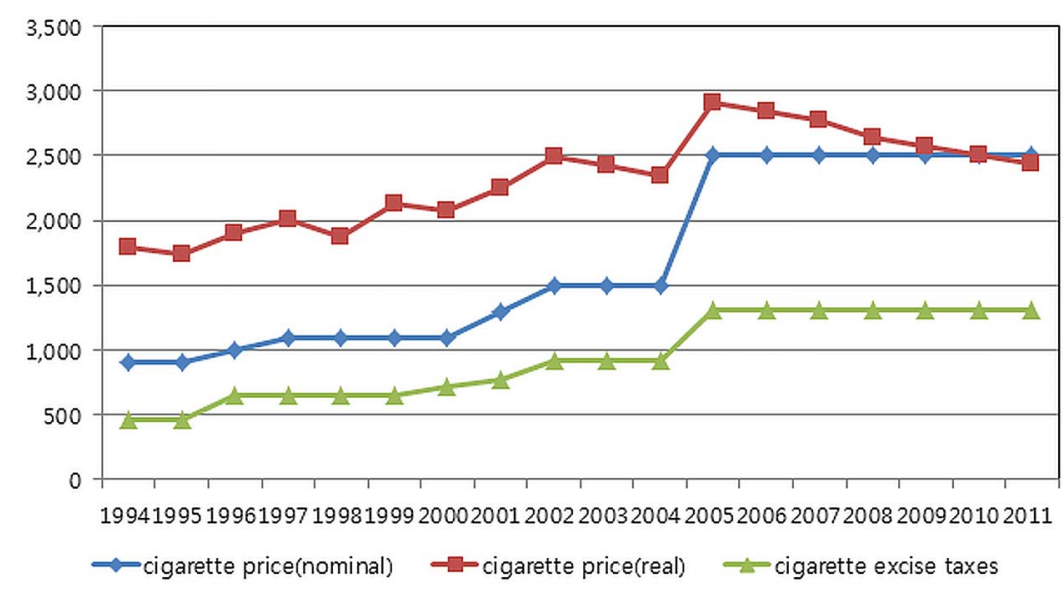

Choi SE. Tob Control 2016;25:141-146. doi:10.1136/tobaccocontrol-2014-051680 
smoking, the date that former smokers quit smoking, the motivation to quit and other information. I use a pooled sample of the 1998, 2001, 2005, 2007, 2008, 2009 and 2010 waves of the KNHNES to analyse the impact of the most significant price increases that occurred after 2001. The strength of the data lies in the fact that they consist of individual cigarette consumption data, while much of the literature uses household expenditure data. The survey asks about average daily cigarette consumption. In addition, the survey includes more recent time-series information than most previous studies, which employ data from the early 2000s when the major price changes had not yet occurred. In the present analysis, the price of a typical pack of 20 cigarettes is deflated using the Consumer Price Index (CPI) with a base year of 1998 to arrive at real cigarette prices.

Table 1 describes the summary statistics of the pooled sample. The sample consists of $28 \%$ smokers and $72 \%$ non-smokers. Approximately $25 \%$ of the non-smokers responded that they were once smokers but had since quit smoking. On average, the non-smokers have higher household income and are older. Most smokers are male, only $12 \%$ of smokers are female. Single and divorced individuals are slightly more likely to smoke. The average duration of smoking is 21 years, and the average consumption of tobacco is approximately 16 packs per month.

\section{Empirical model and estimated results}

The pooled sample consists of $28 \%$ smokers and $72 \%$ nonsmokers. A well-recognised econometric problem with consumption data is the non-random selection of smokers into the sample. Prices and consumption are only observed for current smokers, whereas the entire sample in a given year will also have individuals who, if the prices were lower, might actually smoke. The result of this is that elasticity estimates that use only data on smokers will be biased towards zero, that is, will tend to find less responsiveness to price. I use Heckman's two-stage estimation to determine the price elasticity of cigarette consumption and correct for sample selection bias. Heckman's procedure splits the price-consumption relation into two separate stages: first, the process that determines selection into the sample of smokers, that is, the decision to smoke or not smoke based on a set of latent variables, and second, the number of cigarettes smoked conditional on being a smoker. The empirical model for all income groups consists of the following equations:

$$
\begin{gathered}
Y_{\text {it }}=Y_{\text {it }}^{*} \text { if } Z_{\text {it }} \alpha+\varepsilon_{\text {it }}>0 \\
=0 \text { if } \mathrm{Z}_{\text {it }} \alpha+\varepsilon_{\text {it }} \leq 0 \\
Y_{\text {it }}^{*}=\mathrm{X}_{\text {it }} \beta+\mu_{\text {it }}
\end{gathered}
$$

where $Y_{i t}$ is the natural log of the amount of individual cigarette consumption per day, and $\mathrm{X}_{\mathrm{it}}$ is a vector of variables including age, age squared, female, rural area, single, divorced, widowed, elementary school, middle school, college, no jobs, white-collar, service and sales, agriculture and fisheries, construction, duration of smoking, log real cigarette price per pack of 20 cigarettes and $\log$ income. $Z_{i t}$ in the equation (2) (the selection equation to predict whether an individual is a smoker) includes

\begin{tabular}{|c|c|c|c|}
\hline & Total & Smoker & Non-smoker \\
\hline Dummy variable for smoking & $0.276(0.446)$ & $1(0)$ & $0(0)$ \\
\hline Age (years) & 44.504 (15.916) & $41.378(14.114)$ & $45.611(16.337)$ \\
\hline $\begin{array}{l}\text { Monthly household total income } \\
\text { (million won, nominal income) }\end{array}$ & $331.743(715.431)$ & $311.253(729.345)$ & $339.523(729.345)$ \\
\hline Male & $0.488(0.500)$ & $0.88(0.326)$ & $0.339(0.473)$ \\
\hline Female & $0.512(0.500)$ & $0.12(0.326)$ & $0.661(0.473)$ \\
\hline Rural area & $0.196(0.397)$ & $0.196(0.397)$ & $0.196(0.397)$ \\
\hline \multicolumn{4}{|l|}{ Marital status } \\
\hline Married & $0.689(0.463)$ & $0.654(0.476)$ & $0.704(0.457)$ \\
\hline Never-married & $0.206(0.404)$ & $0.268(0.443)$ & $0.182(0.386)$ \\
\hline Divorced & $0.027(0.163)$ & $0.041(0.199)$ & $0.022(0.147)$ \\
\hline Widowed & $0.072(0.259)$ & $0.029(0.168)$ & $0.088(0.283)$ \\
\hline \multicolumn{4}{|l|}{ Highest level of education } \\
\hline Elementary school & $0.200(0.400)$ & $0.131(0.338)$ & $0.226(0.418)$ \\
\hline Middle school & $0.106(0.307)$ & $0.109(0.311)$ & $0.104(0.306)$ \\
\hline High school & $0.393(0.489)$ & $0.452(0.498)$ & $0.371(0.483)$ \\
\hline College & $0.301(0.459)$ & $0.308(0.462)$ & $0.299(0.458)$ \\
\hline \multicolumn{4}{|l|}{ Occupational category } \\
\hline Professionals, managers & $0.126(0.331)$ & $0.136(0.343)$ & $0.122(0.327)$ \\
\hline White-collar & $0.088(0.283)$ & $0.098(0.298)$ & $0.084(0.278)$ \\
\hline Service and sales & $0.145(0.352)$ & $0.171(0.377)$ & $0.135(0.342)$ \\
\hline Agriculture and fisheries & $0.056(0.230)$ & $0.055(0.227)$ & $0.056(0.231)$ \\
\hline Construction & $0.200(0.400)$ & $0.31(0.462)$ & $0.158(0.365)$ \\
\hline Not holding a job & $0.385(0.487)$ & $0.229(0.42)$ & $0.444(0.497)$ \\
\hline Consumption of cigarettes (number of cigarettes per day) & $4.444(8.422)$ & $15.551(8.617)$ & $0(0.000)$ \\
\hline Duration of smoking (years) & $10.363(13.708)$ & $20.997(12.942)$ & $0(0.000)$ \\
\hline Price (real price, per pack of 20 cigarettes) & $2436.924(300.593)$ & $2423.695(309.293)$ & $2441.954(298.593)$ \\
\hline $\mathrm{N}$ & 54167 & 14071 & 40096 \\
\hline
\end{tabular}
age, age squared, female, rural area, marital status, education,

Table 1 Summary statistics*

*The means are weighted averages using the time-series sample weights that are provided by the survey. 
Table 2 Estimation results for the cigarette demand equation

\begin{tabular}{|c|c|c|c|c|}
\hline & \multicolumn{2}{|c|}{ Two-step estimation } & \multicolumn{2}{|c|}{$\begin{array}{l}\text { Simple ordinary least } \\
\text { squares }\end{array}$} \\
\hline & Coefficient & SEs & Coefficient & SEs \\
\hline Age & $0.058^{* * *}$ & $(0.005)$ & $0.05^{* * *}$ & $(0.003)$ \\
\hline Age squared & $-0.001^{* * *}$ & $(0.000)$ & $-0.001 * * *$ & $(0.000)$ \\
\hline Female & $-1.042^{* * *}$ & $(0.240)$ & $-0.491 * * *$ & $(0.02)$ \\
\hline Rural area & $0.080 * * *$ & $(0.020)$ & $0.041^{* * *}$ & $(0.014)$ \\
\hline Single & $0.091 * * *$ & $(0.025)$ & $0.049 * * *$ & $(0.019)$ \\
\hline Divorced & $0.317^{* * *}$ & $(0.094)$ & $0.097^{* * *}$ & $(0.03)$ \\
\hline Widowed & $0.468^{* * *}$ & $(0.086)$ & $0.255^{* * *}$ & $(0.032)$ \\
\hline Elementary school & 0.029 & $(0.022)$ & 0.007 & $(0.02)$ \\
\hline Middle school & $-0.054^{*}$ & $(0.028)$ & -0.007 & $(0.018)$ \\
\hline College & $-0.126^{* * *}$ & $(0.024)$ & $-0.077^{* * *}$ & $(0.015)$ \\
\hline No jobs & $-0.110^{* * *}$ & $(0.028)$ & $-0.069^{* * *}$ & $(0.022)$ \\
\hline White-collar & -0.018 & $(0.026)$ & -0.026 & $(0.023)$ \\
\hline Service and sales & $0.145^{* * *}$ & $(0.036)$ & $0.099 * * *$ & $(0.022)$ \\
\hline Agriculture and fisheries & -0.011 & $(0.032)$ & 0.006 & $(0.029)$ \\
\hline Construction & $0.102^{* * *}$ & $(0.032)$ & $0.066^{* * *}$ & $(0.021)$ \\
\hline Duration of smoking & $0.016^{* * *}$ & $(0.001)$ & $0.014^{* * *}$ & $(0.001)$ \\
\hline Log price & $-0.425^{* * *}$ & $(0.072)$ & $-0.26^{* * *}$ & $(0.027)$ \\
\hline Log income & $-0.015^{* *}$ & $(0.007)$ & $-0.013^{*}$ & $(0.007)$ \\
\hline Constant & $4.273^{* * *}$ & $(0.362)$ & $3.461 * * *$ & $(0.208)$ \\
\hline Inverse Mills ratio & $0.401^{* *}$ & $(0.193)$ & & \\
\hline
\end{tabular}

Robust SEs are presented in parenthesis, using the Huber/White/Sandwich estimator. ${ }^{*}<0.1,{ }^{* *}<0.05,{ }^{* * *}<0.001$

The excluded categories for sex is male, for rural area is urban, for marital status is married, for education is high school, for occupation is professionals and managers.

job and real price. With the inclusion of duration in the smoking variable, the addictive nature of smoking is reflected in the estimation of the demand equation. This basic econometric model is used to estimate the price elasticity of cigarette consumption for four income groups.
The first stage estimation of decisions to smoke and the second stage estimation of cigarette demand have several implications for smoking prevalence among different socioeconomic groups (see table 2). The dependent variables are a dummy variable for smoking in the first stage estimation (selection equation) and the amount of cigarette consumption per day in the second stage estimation. As with the decision to smoke, the number of cigarettes smoked increases with age. Females, residents of rural areas, single people, and divorced and widowed individuals are less likely to smoke, and smoke smaller amounts than the excluded categories (males and married). More educated and higher income individuals are less likely to smoke and consume fewer cigarettes per day than less educated and lower income individuals. Those who have been smoking for a long time tend to smoke more cigarettes than those who began smoking recently. Price negatively affects smoking participation and the quantity of cigarette consumption. The overall estimated price elasticity of cigarettes is -0.425 . Simple ordinary least squares underestimates the price elasticity of cigarette consumption; the estimated price elasticity without correcting sample selection bias is -0.26 .

\section{Differences in price elasticity by income quartiles}

To examine whether the price elasticity of the lower income group is lower than that of higher income group, I estimate the cigarette demand equation by four quartiles. The second stage estimation in table 2 is repeated for each of the four income groupings, and the results are presented in table 3 . The price elasticity of the lower income quartiles tends to be larger in absolute terms than that of the higher income quartiles. The price elasticity of the first income quartile is estimated to be -0.812 , which is significantly larger in absolute terms than that of the total sample, which is -0.425 . The price elasticity of the second, third and top income quartiles is $-0.572,-0.325$ and -0.341 , respectively. One concern with these elasticity estimates

Table 3 Responsiveness of number of cigarettes smoked by income groups (the second stage estimation results)

\begin{tabular}{|c|c|c|c|c|}
\hline & 1st & 2nd & $3 r d$ & 4 th \\
\hline Age & $0.092^{* * *}(0.012)$ & $0.060^{* * *}(0.012)$ & $0.048^{* * *}(0.01)$ & $0.044^{* * *}(0.012)$ \\
\hline Age squared & $-0.001^{* * *}(0.000)$ & $-0.001^{* * *}(0.000)$ & $-0.001^{* * *}(0.000)$ & $-0.001 * * *(0.000)$ \\
\hline Female & $-1.617^{* * *}(0.394)$ & $-2.129^{* * *}(0.545)$ & $-0.701(0.478)$ & $-0.331(0.543)$ \\
\hline Rural & $0.107^{* *}(0.043)$ & $0.131^{* *}(0.055)$ & $0.060^{* *}(0.029)$ & $0.041(0.038)$ \\
\hline Single & $0.235^{* * *}(0.083)$ & $0.015(0.066)$ & $0.071(0.055)$ & $0.047(0.061)$ \\
\hline Divorced & $0.5912^{* * *}(0.183)$ & $0.607^{* * *}(0.210)$ & $0.139(0.176)$ & $0.241(0.173)$ \\
\hline Widowed & $0.521^{* * *}(0.119)$ & $0.731^{* * *}(0.196)$ & $0.424^{* *}(0.189)$ & $0.277(0.238)$ \\
\hline Elementary school & $-0.024(0.050)$ & $0.007(0.062)$ & $0.013(0.042)$ & $0.041(0.057)$ \\
\hline Middle school & $-0.117^{*}(0.065)$ & $-0.080(0.058)$ & $-0.026(0.055)$ & $0.055(0.081)$ \\
\hline College & $-0.172^{* *}(0.087)$ & $-0.237^{* * *}(0.082)$ & $-0.097^{* * *}(0.032)$ & $-0.123^{* * *}(0.039)$ \\
\hline No jobs & $-0.060(0.110)$ & $-0.230^{* *}(0.092)$ & $-0.087(0.055)$ & $-0.095(0.087)$ \\
\hline White-collar & $-0.020(0.175)$ & $0.028(0.102)$ & $-0.073^{*}(0.041)$ & $-0.020(0.042)$ \\
\hline Service and sales & $0.115(0.123)$ & $0.212^{* *}(0.100)$ & $0.112^{*}(0.064)$ & $0.052(0.088)$ \\
\hline Agriculture and fisheries & $-0.122(0.121)$ & $-0.146(0.109)$ & $0.112^{*}(0.061)$ & $0.103(0.069)$ \\
\hline Construction & $0.066(0.116)$ & $0.147(0.092)$ & $0.100^{*}(0.059)$ & $0.030(0.058)$ \\
\hline Duration of smoking & $0.012^{* * *}(0.002)$ & $0.018^{* * *}(0.002)$ & $0.022^{* * *}(0.002)$ & $0.022^{* * *}(0.003)$ \\
\hline Log price & $-0.812^{* * *}(0.191)$ & $-0.572^{* * *}(0.141)$ & $-0.325^{* *}(0.132)$ & $-0.341^{* *}(0.169)$ \\
\hline Constant & $6.014^{* * *}(1.086)$ & $4.825^{* * *}(0.824)$ & $3.852^{* * *}(0.598)$ & $4.311^{* * *}(0.831)$ \\
\hline Inverse Mills ratio & $1.086^{* * *}(0.348)$ & $1.374 * * *(0.446)$ & $0.180(0.362)$ & $-0.134(0.425)$ \\
\hline $\mathrm{N}$ & 11381 & 13619 & 14834 & 15007 \\
\hline
\end{tabular}

Robust SEs are presented in parenthesis, using the Huber/White/Sandwich estimator.

${ }^{*}<0.1,{ }^{* *}<0.05,{ }^{* * *}<0.001$. 
Table 4 Simulation on the effects of cigarette price increases ( 0.1 million packs, 0.1 million won)

\begin{tabular}{|c|c|c|c|c|c|c|}
\hline $\begin{array}{l}\text { Per cent changes } \\
\text { in price }\end{array}$ & Effects & Total population & 1st & 2nd & $3 r d$ & 4th \\
\hline & Smoking prevalence & $26.3 \%$ & $30.8 \%$ & $25.8 \%$ & $24.6 \%$ & $24.1 \%$ \\
\hline 20 & $\begin{array}{l}\text { Reduction in cigarette consumption } \\
\text { Additional tax revenue }\end{array}$ & $\begin{array}{l}3.69 \\
11200\end{array}$ & $\begin{array}{l}2.0 \\
1496.3\end{array}$ & $\begin{array}{l}1.26 \\
2280.3\end{array}$ & $\begin{array}{l}0.7 \\
3116.5\end{array}$ & $\begin{array}{l}0.7 \\
2786.3\end{array}$ \\
\hline 60 & $\begin{array}{l}\text { Reduction in cigarette consumption } \\
\text { Additional tax revenue }\end{array}$ & $\begin{array}{l}11.07 \\
24600\end{array}$ & $\begin{array}{l}5.9 \\
-264.5\end{array}$ & $\begin{array}{l}3.8 \\
3781.7\end{array}$ & $\begin{array}{l}2.1 \\
7667.2\end{array}$ & $\begin{array}{l}2.0 \\
6750.4\end{array}$ \\
\hline 100 & $\begin{array}{l}\text { Reduction in cigarette consumption } \\
\text { Additional tax revenue }\end{array}$ & $\begin{array}{l}18.45 \\
26100\end{array}$ & $\begin{array}{l}9.8 \\
-8363.2\end{array}$ & $\begin{array}{l}6.3 \\
1204.2\end{array}$ & $\begin{array}{l}3.5 \\
9975.0\end{array}$ & $\begin{array}{l}3.3 \\
8570.0\end{array}$ \\
\hline 140 & $\begin{array}{l}\text { Reduction in cigarette consumption } \\
\text { Additional tax revenue }\end{array}$ & $\begin{array}{l}25.83 \\
15600\end{array}$ & $\begin{array}{l}13.7 \\
-22799.8\end{array}$ & $\begin{array}{l}8.8 \\
-5452.4\end{array}$ & $\begin{array}{l}4.9 \\
10039.8\end{array}$ & $\begin{array}{l}4.6 \\
8245\end{array}$ \\
\hline
\end{tabular}

is the possibility of bias if price increases induce smuggling, in which case demand may be affected by substitution of illegal tobacco products. ${ }^{18} 19$ However, this type of bias is not likely to be large in the case of Korean cigarette demand, since smuggling and substitution of illegal tobacco products is much more limited in Korea than in the USA or European countries.

\section{DISCUSSION}

\section{Differences in consumption and revenue impact of price increases by income quartiles}

Policymakers are often interested in the benefits and relative burdens of policy changes on socioeconomic groups. The results above suggest that lower income Koreans as a group are more responsive to changes in cigarette price than higher income Koreans. Taken together with the fact that lower income Koreans also have a higher smoking prevalence, the finding that lower income smokers cut back on smoking more than higher income smokers implies that the additional tax revenue from cigarette tax increases mostly comes from higher income groups as a whole. Table 4 presents the simulated consequences of alternative cigarette price increases for each of the income groups. The additional tax burdens are primarily borne by the higher income group because higher income people reduce cigarette consumption less in response to price increases than do lower income people. With modest price increases, the tax burden for lower income people rises, but the increase in the tax burden for lower income people is small relative to that for higher income people. A $100 \%$ increase in price would reduce total consumption by $42.5 \%$ and raise over 261 billion won. While all income groups reduce consumption, the revenue increase would primarily come from the top half of the income distribution, while consumption reductions in the lowest quartile would result in their tax spending 83 billion won less on cigarettes. More generally, when the cigarette tax and thus the price of cigarettes increases, the relative tax burdens of high-income and low-income groups change with the tax burden for higher income people rising more than the tax burden for lower income people.

\section{CONCLUSION}

The paper has examined the differential effects of changes in cigarette price on the smoking habits of various income groups in Korea using individual-level cigarette consumption data from the KHNNES. The overall price elasticity of cigarette consumption is estimated to be -0.425 . Cigarette consumption is found to be more price-elastic for lower income than for higher income groups, for a given cigarette price increase in Korea. Smokers in the lowest income quartile reduce consumptions at a rate 2.5 times greater than Korean smokers in the top income quartile. The findings of this paper are consistent with evidence from other high-income countries, implying that cigarette tax and price increases will tend to have a relatively larger impact in improving health outcomes of the poorest Koreans. ${ }^{20} 21$

Given the higher smoking prevalence and the higher share of cigarette expenditure of the poor compared with the rich, cigarette excise taxes tend to be regressive. However, these finding of a higher responsiveness to price changes among lower income individuals implies that the regressivity of cigarette taxes can be reduced through a tax increase. Simulations of the consequences of cigarette price increases show that, for any given change in cigarette taxes and price, the tax burden on lower income people declines relative to that on higher income people.

\section{What this paper adds}

- Taxes on cigarettes are generally known to be regressive, given the higher smoking prevalence and the higher share of cigarette expenditure of lower income groups. However, the regressivity of cigarette taxes can be reduced through a tax increase, if lower income smokers are more price-sensitive than higher income smokers.

- This paper provides new evidence on reduced regressivity of cigarette tax through a tax increase by analysing the patterns of price elasticity of cigarette consumption of different income groups in Korea. In particular, in Korea, lower income smokers respond more strongly than higher income smokers to cigarette price increases, and reduce their cigarette consumption more.

- The tax burden on lower income Korean smokers declines relative to that on higher income smokers, implying that the cigarette tax can be less regressive through a tax increase in Korea.

Acknowledgements This paper is rewritten based on the KIPF research paper on the fiscal effect of tobacco taxation. Seok Jin Woo and Hee Cheol Min gave useful comments on the paper.

Competing interests None.

Provenance and peer review Not commissioned; externally peer reviewed.

Data sharing statement The KNHNES data are available at https://knhanes.cdc. go.kr/knhanes/index.do

\section{REFERENCES}

1 OECD. OECD Factbook 2013.

2 Ministry of Health and Welfare. Ministry of Health and Welfare Statistical Yearbook, 2013. 
3 Kim WN, Lee C. An estimation of the price elasticities of tobacco and health demand of Korean urban households using macro and micro level data. Korean Demogr 2002;25:257-89.

4 Lee Y, Na SL. Estimation of the elasticity of tobacco products with Korean time series data. Korea Econ Stud 2007;19:151-71.

5 Min HC. Estimation of tobacco products demand with discrete choice model. Public Finance Forum 2007; 12:27-42.

6 Kim WN. An estimation of the price elasticity for tobacco demand. Korean Demogr 2004;27:81-90.

$7 \mathrm{Kim}$ WN, Suh JH. Estimation for the price elasticity of tobacco and health demands in the urban households. Korean Demogr 2005;28:133-47.

8 Kim WN, Suh JH, Kim YJ. The effect of price increase on tobacco consumption. Korean Demogr 2006;29:195-213.

9 Sung MJ, Kim JS, Park SW, et al. Optimal taxes on tobacco products. Seoul: Korea Institute of Public Finance, 2008.

$10 \mathrm{Hu}$ TW, Mao Z. Effects of cigarette tax on cigarette consumption and the Chinese economy. Tob Control 2002;11:105-8.

11 John RM. Price elasticity estimates for tobacco products in India. Health Policy Plann 2008:23:200-9.

12 Lee JM, Liao DS, Ye CY, et al. Effect of cigarette tax increase on cigarette consumption in Taiwan. Tob Control 2005;14:71-5.
13 Ohsfeldt RL, Boyle RG, Capilouto El. Tobacco taxes, smoking restrictions, and tobacco use. In: Chaloupka FJ, Grossman M, Bickel WK, Saffer H, eds. The economic analysis of substance use and abuse: an integration of econometrics and behavioral economic research. NBER: University of Chicago Press, 1999:15-30.

14 Gallet CA, List JA. Cigarette demand: a meta-analysis of elasticities. Health Econ 2003;12:821-35

15 WHO, World Bank. Tobacco control in developing countries. 2000.

16 International Agency for Research on Cancer. Handbook of cancer prevention in tobacco control. Volume 14. Effectiveness of Tax and price policies for tobacco control. Lyon, France: IRAC, 2011.

17 World Bank. Economics of tobacco toolkit. 2011.

18 Coady MH, Chan CA, Sacks R, et al. The impact of cigarette excise tax increases on purchasing behaviors among New York city smokers. Am J Public Health 2013; 103:54-65

19 Gruber J, Sen A, Stable M. Estimating price elasticities when there is smuggling: the sensitivity of smoking to price in Canada. J Health Econ 2003;22:821-42.

20 Guindon GE, Nandi A, Chaloupka FJ, et al. Socioeconomic differences in the impact of smoking tobacco and alcohol prices on smoking in India. NBER Working Paper 2011;17580

21 Siahpush M, Wakefield M, Spittal M, et al. Taxation reduces social disparities in adult smoking prevalence. Am J Prev Med 2009;36:285-91. 